\title{
0 acesso ao livre brincar: Elevando o potencial de resiliência
}

\author{
The access to playing: Raising the resilience potential
}

Luciana Cassarino Perez ${ }^{[a]}$, Ana Paula Almeida de Pereira ${ }^{[b]}$

\footnotetext{
${ }^{[a]}$ Psicóloga formada pela Universidade Federal do Paraná (UFPR), Curitiba, PR - Brasil, e-mail: lucicaspe@onda.com.br; luciana.perez@hpp.org.br

${ }^{[b]}$ Professora adjunta do Departamento de Psicologia da Universidade Federal do Paraná (UFPR), Curitiba, PR-Brasil, e-mails: anapaula_depereira@yahoo.com; anapaula_depereira@ufpr.br
}

Recebido: 06/09/2010 Received: 09/06/2010

Aprovado: 29/10/2010 Approved: 10/29/2010

\section{Resumo}

Este artigo apresenta os resultados de três estudos de caso de meninos em situação de risco, estudos que tiveram como propósito compreender como o brincar contribui para que essas crianças se tornem resilientes. Os três participantes da pesquisa são pacientes de uma Associação que oferece atendimento psicológico e um espaço terapêutico diferenciado, a brinquedoteca. Observações do livre-brincar realizado pelos três meninos nesse espaço, assim como entrevistas semidirigidas, foram os procedimentos metodológicos utilizados. Os dados obtidos foram submetidos à análise qualitativa fenomenológica com foco no individual e peculiar. Concluiu-se que o brincar ocupa um espaço importante na vida dessas crianças, pois garante a expressão de sentimentos, o resgate da infância perdida, a formação de vínculos afetivos e a manutenção da esperança em um futuro melhor. Tais condições contribuem para que os meninos possam superar adversidades já enfrentadas e outras que estejam por vir, aumentando-lhes o potencial de resiliência.

Palavras-chave: Resiliência. Livre-brincar. Risco.

\section{Abstract}

This article presents the results of three case studies of boys under risk situation. The studies had the purpose of understanding how can the act of playing contribute to making those children resilient. The three participants of the research are patients of an Association that offers psychological treatment and a differentiated therapeutic place called toy-library. Observations of the "free-playing" made by the three children in that place, as well as semi-structured interviews, were the methodological procedures used. The data acquired were submitted to a phenomenological qualitative analysis, focused on the peculiar and individual factors. The conclusions were that playing is an important part of children life because it guarantees the expression of feelings, the rescue of lost infancy, the formation of affective bonds and the maintenance of hope in a better future. These conditions contribute so that these children can overcome adversities already faced, and others that may come, by increasing their resilient potential.

Keywords: Resilience. Free-playing. Risk. 


\section{Introduç̃̃o}

A junção de uma experiência profissional com o interesse por um conceito atualmente empregado no campo da psicologia foi a porta de entrada para este estudo sobre resiliência e sua relação com os efeitos positivos do brincar.

A experiência profissional se deu em uma organização não governamental (ONG) de Curitiba, cujo objetivo é atender crianças e adolescentes, por meio de uma equipe interdisciplinar de profissionais especializados em saúde mental, na qual o eixo terapêutico é o brincar e o fazer criativo, articulado à palavra. 0 brincar possui um lugar de destaque na ONG, a brinquedoteca, uma sala de espera um tanto diferenciada, na qual crianças e adolescentes têm acesso ao que se convencionou chamar de "livre-brincar". Os efeitos positivos que puderam ser observados nas crianças frequentadoras da brinquedoteca inserida na clínica interdisciplinar fizeram surgir a necessidade de um estudo mais aprofundado, que pudesse dar embasamento teórico ao projeto. Nesse sentido, a pesquisa teve como foco central identificar sinais de resiliência nas crianças que frequentam a brinquedoteca, tendo como foco a seguinte pergunta de pesquisa: "Como o livre-brincar e as experiências positivas que este brincar proporciona contribuem para que crianças institucionalizadas se tornem indivíduos resilientes?".

Inicialmente resiliência era um conceito restrito às áreas da Física e da Engenharia e dizia respeito à relação entre a energia armazenada por um corpo e a deformação produzida no mesmo. Há pouco mais de 20 anos, a Psicologia tem se ocupado desse fenômeno. Yunes (2006) afirma que a definição de resiliência na Psicologia ainda não é tão clara e precisa quanto a da Física e das Engenharias. Entre as definições que se encontram hoje na literatura, destaco a de Zimmerman e Arunkumar (1994) de que a resiliência refere-se a uma habilidade de superar adversidades. Em termos gerais, pode-se dizer então que o indivíduo resiliente, ao longo de sua vida, adquire recursos que possibilitam a superação de situações de risco. É importante ressaltar que "A resiliência se expressa frente à presença de fatores de risco. Não existirá resiliência sem o risco" (Paludo \& Koller 2005, p. 2). A perspectiva desses autores foi adotada como referência na pesquisa.

Este estudo traz um conceito que, assim como o trabalho realizado na brinquedoteca na ONG, é pioneiro. São escassas as referências na literatura da psicologia sobre o que, por influência da Associação Brasileira de Brinquedotecas, a instituição convencionou chamar de "livre-brincar". Entende-se essa forma de brincar como tendo um fim por si próprio, pelo puro prazer de brincar, ou seja, ele acontece, pois corresponde ao desejo da criança que o realiza.

Segundo Bomtempo (1999), o brincar é uma atividade social e cultural que pressupõe aprendizado, reflete aspectos da cultura de um povo e está inserido nessa cultura. Esta autora acredita ainda que "a brincadeira aparece, assim, como meio de sair do mundo real para descobrir outros mundos, para se projetar num universo inexistente" (Bomtempo, 1999, p. 52).

O brincar, segundo Medrano (2004), apareceu mais recentemente no cenário social atual, a partir de espaços específicos para a realização dessa atividade. 0 autor acredita que o aparecimento desses espaços se deve à inclusão do Direito ao Brincar na Convenção Internacional dos Direitos da Criança, ${ }^{1} \mathrm{e}$ ao seu correlato no Brasil no Estatuto da Criança e do Adolescente (ECA).

Reconhecendo o Direito ao Brincar, a brinquedoteca da ONG se constitui como espaço para a realização da brincadeira espontânea proposta. Magalhães e Pontes (2002) afirmam que, apesar da grande difusão destes ambientes nos últimos anos, "poucos estudos são encontrados na literatura relatando os aspectos essenciais para criação e manutenção de uma brinquedoteca" (Magalhães \& Pontes, 2002, p. 136).

\section{Método}

\section{Participantes}

Definiu-se como população crianças do sexo masculino, retiradas dos pais pelo Conselho Tutelar. Com base em Yunes e Szymanski (2002), consideraram-se

\footnotetext{
1 Artigo 31:1. Os Estados Partes reconhecem o direito da criança ao descanso e à distração, ao brincar e às atividades recreativas próprias para a sua idade, e a participar livremente na vida cultural e nas artes.
} 
como fatores de risco as seguintes situações: pobreza, baixa escolaridade dos pais, estresse perinatal, baixo peso no nascimento, ou, ainda, a presença de deficiências físicas.

Os meninos escolhidos para fazer parte da população têm 13 anos e vivem em um abrigo na cidade de Curitiba, mantido pela Fundação de Ação Social (FAS). Chegaram a essa casa, onde moram em média 30 crianças, vítimas de violência doméstica e com indícios de profundo sofrimento mental.

Da população escolhida, composta por crianças institucionalizadas e em atendimento psicológico na Associação, delimitou-se uma amostra de três crianças. A amostra foi definida com base em observações realizadas ao longo de um período de dois anos do cotidiano da brinquedoteca. Na função de "educadora brinquedista" voluntária da brinquedoteca da instituição, houve a possibilidade de definir a amostra de acordo com os requisitos da pesquisa.

\section{Desenho metodológico e procedimentos}

O desenho metodológico adotado nesta pesquisa foi do tipo qualitativo fenomenológico. Segundo Bicudo e Martins (1989), a pesquisa qualitativa fenomenológica está interessada em compreender os fenômenos e não em explicar fatos. 0 foco está no individual e peculiar, deixando de lado as generalizações típicas da pesquisa quantitativa.

Para proporcionar uma descrição substancial do fenômeno investigado (o fenômeno da resiliência), utilizou-se como estratégia metodológica o estudo de caso. Essa estratégia permitiu um foco bastante individual e peculiar da amostra de pesquisa, possibilitando atingir o desvelamento do fenômeno da resiliência assim como a compreensão do mesmo.

Diferentes procedimentos foram utilizados a fim de atingir os objetivos do estudo: observações, entrevistas com as crianças e entrevistas com cuidadores e familiares. Optou-se por duas fontes de obtenção de dados (entrevistas e observações), para tornar a pesquisa o mais fidedigna possível. Nesse sentido, procurou-se ainda realizar mais de uma entrevista e várias observações do brincar de cada criança.

Os momentos de observação do "livre-brincar" desempenhado pelas crianças realizaram-se na brinquedoteca. 0 processo de observação durou seis semanas, considerando que as crianças frequentam a brinquedoteca uma vez por semana e que todas elas tiveram faltas ao longo do processo, totalizaram-se quatro sessões de observação com cada menino. As sessões tiveram duração ininterrupta de aproximadamente vinte minutos e foram filmadas, com a autorização da diretora do abrigo, responsável pelos meninos.

As entrevistas foram semidirigidas, o que significa que o roteiro de entrevista foi elaborado na intenção de manter o foco na pergunta-problema da pesquisa, mas em momento algum significou uma forma de controlar as respostas, limitando-as àquilo que foi previamente perguntado. Os roteiros foram adaptados para três grupos diferentes de pessoas: os participantes da pesquisa; os cuidadores no abrigo e os familiares dos participantes. 0 total de entrevistas realizadas foi de 12 , sendo que três entrevistas foram com os meninos (participantes da pesquisa), seis com os educadores, duas com irmãos e uma com uma mãe.

A análise dos dados coletados seguiu, portanto, o desenho qualitativo fenomenológico. Após o término das observações e entrevistas, todo o material referente aos três sujeitos foi submetido a uma primeira leitura mais detalhada, a partir da qual surgiram as principais impressões. Em seguida, realizou-se uma segunda leitura ainda mais rigorosa, na qual os assuntos presentes nos relatos foram divididos em categorias, tendo sempre como foco responder a pergunta-problema. Formulou-se uma lista de categorias para os temas presentes nas entrevistas, e outra lista para os temas presentes nos relatos das observações. Num terceiro momento ocorreram as comparações, com objetivo de encontrar semelhanças e peculiaridades significativas para a descrição do fenômeno estudado. As comparações foram feitas entre as entrevistas referentes a um mesmo sujeito - diferentes discursos sobre uma mesma criança - e entre os dados obtidos de cada sujeito - diferentes crianças com diferentes formas de brincar e se relacionar.

\section{Resultados e discussão}

\section{Histórias de vida, relações e características individuais}

Entendendo que a noção de resiliência pressupõe que o indivíduo esteja exposto a situações de risco, parte importante dos resultados da pesquisa se localizou na história de vida, formas de se relacionar e 
características individuais de cada um dos três meninos participantes da pesquisa.

As histórias de vida perpassadas por fatores de risco como: violência doméstica; uso de drogas; famílias numerosas; escassez de recursos; entre outros, justificaram a necessidade de se estudar resiliência nesses casos. Além das histórias de vida, as características de cada um revelaram muito a respeito do que eles já conquistaram e ainda podem conquistar em termos de resiliência. Em relação às formas de se relacionar, algumas se constituíram como risco, enquanto outras foram construídas na tentativa de superar tamanhas adversidades.

Utilizando pseudônimos a fim de preservar a identidade dos participantes da pesquisa, chamei os meninos de: Cláudio, André e Diego.

Diego foi vítima de violência doméstica e, por meio de uma denúncia feita por ele, foi levado para o abrigo onde morava desde 2005. Seus relatos e dos educadores apontam pouco contato com a família desde o abrigamento. Apesar disso, o menino afirma constantemente que quer voltar a morar com a família. Segundo os educadores, na relação com eles Diego é agressivo, está constantemente a afrontá-los. Em contrapartida, os educadores afirmam que a relação com outros meninos da casa é mais harmoniosa, e o próprio Diego fala muito de seus amigos ali. Não é uma criança que busca vincular-se com alguém em especial, mas tem mais contato com os educadores homens. Na escola, Diego tem muita dificuldade, atribuída pelos educadores à falta de empenho, já que, segundo eles, o menino tem muita inteligência, prática na resolução de problemas, assim como um potencial artístico e criativo.

André está em situação de abrigamento desde 2003. Ele foi entregue ao Conselho Tutelar pela própria mãe, que, em entrevista, disse não ter condições financeiras de manter os filhos. André é portador de uma doença crônica, a epilepsia refratária, doença à qual ele próprio atribui suas principais dificuldades. Por ser portador de epilepsia, André possui alguns privilégios que outros meninos da instituição não têm. Essa peculiaridade foi apontada pelos educadores como causa do relacionamento conturbado e agressivo com os outros meninos da casa. Na relação com os educadores existe uma demanda por atenção e exclusividade. André costuma fazer vínculos especiais com pessoas que cita constantemente, como com a mãe, uma namoradinha da escola e a diretora do abrigo. Enquanto esteve abrigado, André frequentou uma escola especial, a partir de um diagnóstico de deficiência mental leve, consequência das sequelas deixadas pelas crises convulsivas.

Cláudio está abrigado acompanhado de um irmão mais novo, com o qual tem bastante afinidade. É uma criança que quase não tem referência de pais, pois, desde 2003, está em situação de abrigamento, tendo passado por outra instituição antes desta. Os educadores ressaltam que Cláudio busca se vincular às mulheres com quem tem mais contato, apelidando-as de "mãe sociais". Sua busca por aproximação foi descrita por essas mulheres como "irritante", pois envolve uma insistência grande. Sobre a relação com os colegas da casa, Cláudio diz que tem muitos amigos e costuma brincar com eles. Enquanto sua maior habilidade é com o esporte, na escola Cláudio encontra seus maiores desafios. Os educadores se preocupam, pois acreditam que ele tem dificuldade para compreender coisas simples.

\section{A diversidade do brincar}

A riqueza desta pesquisa qualitativa, é graças principalmente às peculiaridades, à diversidade presente nesses três meninos. As diferenças individuais se evidenciaram não apenas nas características pessoais e na forma de se relacionar dos meninos. Cada um deles encontrou, em diferentes atividades, suas formas de brincar e elaborar questões. Torna-se fundamental, portanto, uma descrição geral dos tipos de brincadeira que mais apareceram - o faz-de-conta; a brincadeira ao ar livre; os jogos de tabuleiro; formas próprias de brincar; música e dança - para finalmente compreendermos os atributos que cada brincar pode possuir.

Segundo Santa Roza (1999), a brincadeira "É um estado de 'faz-de-conta', aquilo a que as crianças tão propriamente se referem como sendo não 'de verdade', mas 'de brincadeira'” (Santa Roza, 1999, p. 37). 0 brincar de faz-de-conta permite experimentar uma série de atividades que não são acessíveis às crianças, geralmente por se tratarem de atividades 'do mundo adulto'. Isso significa que a experiência proporcionada pela brincadeira de faz-de-conta permite que as crianças "vivenciem suas ideias, em nível simbólico, para poderem compreender seu significado na vida real" (Cunha, 2001, p. 22). 
0 faz-de-conta apareceu em diversos momentos de observação e entrevista. Todos os sujeitos pesquisados ou descreveram uma situação de faz-de-conta, ou vivenciaram-na no espaço da brinquedoteca. Tal espaço possui um "canto" dedicado especialmente a esse tipo de brincadeira, no qual se encontram brinquedos como: bonecas, casinhas, fantoches, carrinhos, fantasias, etc.

Diego elegeu como sua brincadeira favorita, durante as entrevistas, as fantasias. Afirmou que com elas podia assumir personagens, brincar, tirar fotos e fazer as outras pessoas ficarem alegres. Em uma das observações Diego encontrou uma marreta de plástico de cor amarela e saiu batendo nas pessoas e objetos afirmando ser o "Chapolin Colorado". Nessa situação, suas batidas foram cada vez mais frequentes e fortes, como se quisesse expressar algum sentimento por meio daquelas batidas barulhentas.

Assumir um personagem, como no caso de Diego, pode ser uma forma de se familiarizar com desejos próprios e expressá-los. Segundo Bettelheim (1989), enquanto preenche seus desejos de grandeza, imaginando ser um personagem que tem poderes, a criança busca também, além da satisfação de devaneios irreais, o controle de outras pessoas. A última característica é muito frequente em Diego, que sempre tenta persuadir e influenciar outros para conseguir o que deseja, principalmente quando se trata dos adultos que exercem autoridade.

Os atributos presentes neste tipo de brincadeira são especialmente importantes para a compreensão de como o brincar pode elevar o potencial de resiliência de crianças e adolescentes. Segundo Bettelheim (1989), a partir das fantasias imaginativas e das brincadeiras baseadas nelas, que a criança começa a colocar em ordem seu mundo caótico interior, e a compensar alguns dos inconvenientes que sofre na vida e que muitas vezes têm origem no seu próprio inconsciente. Ao colocar em ordem seu mundo interior, a criança está dando um passo importante para se libertar do que possui, mas não deseja e, consequentemente, está aumentando sua capacidade de enfrentar a realidade. Toda vez que se torna difícil manipular a realidade, a fantasia pode ser um caminho para tornar as limitações dessa realidade visíveis, só que por meio da atividade lúdica.

A brincadeira ao ar livre foi muito experimentada no ambiente protegido do pátio da brinquedoteca. Verden-Zöller (2004) afirma que os ambientes desprotegidos das grandes áreas metropolitanas não permitem às crianças sensações de confiança e aceitação, impedindo também o desenvolvimento integral de funções naturais como auto-orientação, autorrespeito, responsabilidade social, liberdade e amor. Apesar de a autora não se referir diretamente ao potencial de resiliência que as brincadeiras em lugar seguro podem proporcionar, as funções descritas por ela envolvem características diretamente ligadas ao conceito principal desta pesquisa. Portanto, oferecer às crianças um espaço livre, que seja seguro e disponível para diversos tipos de brincadeira (jogar bola, soltar pipa, jogar bolinha de gude, pular corda...), pode conduzir a resultados importantes no que diz respeito ao potencial de resiliência alcançado por cada uma.

Um terceiro tipo de brincar, os jogos de regras, também possuiu um espaço importante dentro da brinquedoteca para essas crianças. São um tipo de brincadeira que revela muito o sujeito que brinca. Cunha (2001) afirma que uma das características mais peculiares do jogo é a necessidade de um parceiro para jogar. Existe neste brincar uma relação de competitividade e cumplicidade ao mesmo tempo, já que ambos têm o objetivo de realizar o jogo. Segundo a autora, é essa relação que revela e expõe as potencialidades e dificuldades do jogador, assim como suas emoções e a capacidade de lidar com limites.

Segundo Bettelheim (1989), o jogo de regras é extremamente eficaz na forma como ajuda a criança a adquirir, passo a passo, a capacidade de enfrentar a realidade social e tudo o que ela envolve. Jogar permite experimentar limites, regras, frustrações e derrotas, como que num ensaio para o que é a vida em sociedade.

Embora os jogos tenham sido citados como brincadeiras favoritas por dois dos meninos, pouco uso fizeram deles nos momentos de brincar observados. As histórias de vida antes do abrigamento (sem limites e regras) e a forma como esses meninos estão marginalizados em relação às outras crianças da sociedade, permitem inferir que exista a dificuldade de enfrentar uma brincadeira que explicita questões que podem ser difíceis de assimilar para André, Cláudio e Diego.

Nos poucos momentos de interação com jogos de regras na brinquedoteca, alguns efeitos positivos puderam ser observados principalmente em relação à inclusão. No caso de Cláudio, sempre que 
via outras crianças jogando, parava para observar, demonstrando um possível interesse no jogo, mas geralmente se recusando a participar. Em determinada situação, ao observar uma educadora brinquedista e outra criança jogando Detetive, Cláudio foi convidado para jogar. Depois de muita insistência, resolveu participar, sendo incluído no mundo das regras, acompanhado por uma das brinquedistas na aventura que o jogo propunha: descobrir, dentre outras coisas, o responsável por um assassinato. A experiência com regras pôde ser vivida por Cláudio também em seus jogos de futebol no pátio da instituição, já que estes, mesmo adaptados ao espaço reduzido, estavam pautados por alguns limites que deveriam ser respeitados pelos jogadores.

Não só os jogos, mas todo tipo de brincar diz muito sobre o sujeito. Nesse sentido, cada criança cria suas formas próprias de brincar, aquelas que atendem aos seus propósitos e necessidades. Sobre isso, vários autores destacam que a brincadeira (e principalmente o brinquedo) não tem existência própria, ou seja, só teremos um brinquedo ou uma ação de brincar na medida em que exista alguém que brinque. Medrano (2004) afirma, por exemplo, que um pedaço de pau só se transforma em espingarda depois que a criança se transformou em soldado. Cada brinquedo, portanto, pode ter funções e sentidos diferentes para cada criança, assim como qualquer objeto pode ser transformado pela mesma em brinquedo.

Formas próprias de brincar e objetos que inicialmente não seriam considerados brinquedos foram muito utilizados pelos três participantes da pesquisa. Diego teve um momento de contato com um objeto para bebês (uma espécie de móbile) que na sua brincadeira teve outra função da normalmente atribuída para aquele objeto. André tinha o costume de carregar com ele pequenos objetos, como tampinhas de garrafa, chaveiros, chaves e outras miudezas. A diretora do abrigo trouxe, em um de seus relatos, um pouco da riqueza envolvida nesse tipo de brincar:

[...] o André é o tipo da pessoa que gosta de algumas argolas, miniaturas de bichinhos, sabe? Parece até que aquelas coisas são como ícones pra ele, é muito engraçado [...] entrega um pacote de bugigangas e badulaques pro André e deixa ele sozinho! Ele passa horas assim, é gostoso de ver como ele se relaciona com esses objetos.

A música e a dança foram duas formas de expressão muito citadas em quase todas as entrevistas como sendo um dos maiores interesses dos meninos. Foram utilizadas também em conjunto com brinquedos, e consideradas na pesquisa como outro tipo de brincar. Dançar e cantar parecem ter um sentido todo especial para esses meninos, as duas formas de expressão possibilitam dizer coisas que não aparecem em conversas ou outros tipos de brincadeira. Assis, Pesce e Avanci (2006) atribuem sentidos a esse tipo de expressão artística. Segundo as autoras, a dança e a música permitem superar adversidades, pois, por meio delas, crianças e adolescentes reelaboram e representam de outra forma o sofrimento vivido em determinado episódio social.

Dentre os meninos observados, André parece ter um interesse especial por música, pois suas brincadeiras são sempre ao som de canções que ele mesmo canta. Os educadores destacaram, em seus relatos, que o menino costuma cantar muito também no abrigo, e que as temáticas das canções às vezes dizem a respeito ao momento pelo qual ele está passando:

[...] Ele gosta de cantar, ele adora cantar. Um dia ele cantou uma música que ele chamou extrema atenção, assim, um momento que ele queria muito, ele estava muito num processo de cura, e hoje parece que ele já esqueceu isso. Daí ele cantava assim... Eu acho que a mãe dele andou levando ele pra Igreja Evangélica, porque ela diz que lá Jesus vai curar [...] e ele dizia assim: 'A doença sairá! ' não me pergunte que ritmo... 'A doença sairá, o satanás sairá, o capeta sairá!!!!

\section{Possibilidades e efeitos do brincar}

"A intensidade e o poder de fascinação de um jogo (brincadeira) são suas características primordiais e não podem ser explicadas por análises biológicas" (Santa Roza, 1999, p. 29).

O encantamento - ou fascinação como coloca Elisa Santa Roza (1999) - acredito ser, indiscutivelmente, o mais importante dos efeitos que qualquer brincar oferece. Uma criança fascinada por uma brincadeira leva consigo experiências inesquecíveis para a vida toda, experiências positivas às quais pode recorrer em caso de dificuldade extrema. 0 brincar tem o poder de encantar e manter a esperança em dias melhores, facilitando a superação de dificuldades e aumentando o potencial de resiliência da criança que brincou. Brincadeira como refúgio. 
Ao longo da pesquisa pode-se perceber, dentre outras possibilidades, que o brincar se constitui para os meninos, como uma forma de suavizar o sofrimento tão presente em suas vidas. Algumas situações específicas observadas puderam ser interpretadas como "escapadas" desses meninos para situações de menos risco:

- Diego, tirando fotografias com roupas diferentes e acessórios, abraçado a colegas e educadores da Associação, na tentativa de registrar vínculos que não possui, assim como bens materiais que não lhe pertencem.

- André, com suas viagens à fantasia incorporando ninja ou animal selvagem (jacaré), para experimentar sensação de poder, força e vitalidade, características muito distantes da sua realidade de fragilidade e doença.

- Cláudio, jogando futebol no pátio da instituição, driblando seus colegas e "fugindo" para um estádio de futebol, ao qual nem sempre tem acesso.

Um porto seguro, de vez em quando, pode ser experimentado com o acesso ao brincar. Portanto essa atividade não diz respeito somente à construção da subjetividade, mas, como infere Medrano (2004), tem também a função de sustentar a capacidade de suportar os infortúnios das histórias de vida familiar e social das crianças. No caso de Cláudio, André e Diego, a brincadeira permite "fugir", por alguns momentos, da epilepsia, da pobreza, do abandono, da dificuldade escolar, do sofrimento psíquico, dentre outras adversidades às quais estão permanentemente expostos.

\section{Brincar dando acesso ao futuro}

Uma ligação muito forte entre as brincadeiras escolhidas e a profissão que as três crianças desejam para seus futuros, puderam ser percebidas. Entendo que proximidade não se dá a toa, já que o brincar pode ajudar esses meninos a se sentirem mais próximos do que desejam para seus futuros. Assim como, por meio da brincadeira, as escolhas profissionais podem ser amadurecidas à medida que as crianças se tornam adolescentes.

Com a relação à forma como o brincar pode conduzir ao futuro, Bettelheim (1989) coloca que uma escolha profissional pode, sim, vir de uma espontânea insistência em uma determinada brincadeira e seus correlatos, e, se assim for, as lembranças positivas desse brincar podem acrescentar vida à realização dessa atividade no futuro.

Por outro lado, Bettelheim (1989) acredita que, na maioria das vezes, a criança que insiste, por vontade própria, em uma determinada brincadeira, está tentando resolver algo interno, algo que a preocupa. A insistência nesse brincar é uma forma de "extravasar" essa preocupação interna, e sempre que o objetivo for atingido, a brincadeira acabará por se esvair. Tendo cessado suas questões, o indivíduo adulto poderá abraçar uma carreira completamente diferente da sugerida por suas brincadeiras infantis, sem que haja arrependimento, pois terá experimentado e até se fartado dessa outra atividade.

Para ilustrar a forma como a brincadeira se repetiu e esteve ligada aos desejos de profissão dos meninos, o caso de Cláudio me parece o mais evidente. Ele sempre afirmou que no futuro gostaria de se tornar um jogador de futebol e jogar no time pelo qual torce. As brincadeiras de Cláudio estiveram de forma direta, ou a partir de correlatos, ligadas a essa temática, assim como as conversas comigo e com os colegas de brinquedoteca. A possibilidade de brincar e explorar esse "universo futebol" pode não só diminuir a distância entre presente e futuro, mas principalmente manter a esperança desse garoto em uma vida futura feliz e repleta de realizações pessoais.

Grotberg (1995) afirma que a criança que está confiante de que seu futuro será feliz tem maiores possibilidades de superar adversidades no caminho pela conquista desse objetivo. Segundo a autora o "eu sou" ou "eu estou" ( $\mathrm{I} \mathrm{am}$ ) se constitui como uma das três fontes de resiliência. Estar certo de um futuro melhor (no caso destes meninos) e, portanto, mais feliz, é uma das questões que cada criança pode retirar dessa fonte intitulada pela autora de "eu sou". No caso de Cláudio, por exemplo, apegou-se a brincadeira de futebol, e tudo o que ela envolve, supostamente para ter mais confiança de que seu futuro será feliz, mantendo a esperança nessa realização futura.

\section{Brincadeira como forma de superar dificuldades}

A grande questão deste estudo foi referendar que a disponibilidade de um espaço no qual a brincadeira se tornou acessível e livre para cada um deles permite a elaboração e a construção de um caminho para 
superar algumas das dificuldades vividas. Nesse sentido, o livre-brincar pôde ser entendido como forma de tornar esses indivíduos cada vez mais resilientes, perante o grande número de fatores de risco aos quais ainda estão expostos.

Concordando com a ideia de que o brincar facilita a superação de situações adversas, Santa Roza (1999) afirma que as brincadeiras nem sempre estão relacionadas à obtenção de prazer. Segundo ela, realizar brincares específicos como os que foram realizados por Cláudio, André e Diego, pode ser uma tentativa de elaborar algo impressionante, principalmente quando essa brincadeira se repete muitas vezes. Além de elaborar conteúdos difíceis, a criança pode estar buscando dominar a situação e dar sentido ao ocorrido.

A possibilidade de superação das dificuldades cognitivas se torna especialmente importante no caso dos três meninos em questão. Principalmente o jogo de regras, quando se torna de alguma forma atraente para o jogador (no caso de Cláudio foi por meio dos colegas e da mediação do educador brinquedista), pode trazer benefícios importantes para a cognição das crianças. A partir desse tipo de brincadeira, as crianças podem, por exemplo, adquirir vocabulário e conceitos novos, e exercitar o pensamento abstrato e a simbolização. Segundo Cunha (2001), explorar a curiosidade natural da criança pode ser um meio de favorecer o aprendizado de coisas novas. A autora acredita que, "através dos jogos e brincadeiras, a criança pode aprender novos conceitos, adquirir informações e até mesmo superar dificuldades de aprendizagem" (Cunha, 2001, p. 28).

Em termos de superação de dificuldades, um destaque importante deve ser feito para o caso de André. Este menino, que possui uma doença crônica, tem uma saúde muito debilitada, que por vezes até impediu que ele fosse à Associação receber atendimento. Entretanto, André participou ativamente do cotidiano da brinquedoteca nos dias em que pôde frequentá-la, mesmo mostrando sinais evidentes de cansaço após, por exemplo, jogar futebol. A percepção obtida foi a de que este menino tem uma enorme vontade de superar as dificuldades dessa doença e de ser uma criança ativa e feliz como as que são saudáveis. Para superar essa condição de doente, pude perceber que André recorre muito à brincadeira, usufruindo do espaço e dos brinquedos mais do que qualquer outro paciente.

\section{Brinquedoteca e livre-brincar no contexto social}

O contato social também é favorecido por meio do livre-brincar, já que a brinquedoteca é um espaço sócio-educativo, no qual convivem crianças de todas as idades, classes sociais e com diversos tipos de dificuldade.

A variedade de encontros e a possibilidade de participar de brincadeiras com outras crianças ampliam a rede de contato desses meninos fora do abrigo, e lhes possibilita um "ensaio" para o que a vida lhes reserva fora do ambiente protegido de abrigamento. Além disso, as crianças que sofrem muito preconceito pela classe social, pela doença e pela condição de abrigamento, encontram, no espaço da brinquedoteca, a possibilidade de serem vistos como crianças com as mesmas possibilidades, direitos e obrigações de todas as outras.

\section{Mediaccão do educador brinquedista}

Esta pesquisa elucidou algumas questões que estavam um tanto encobertas em relação ao livre-brincar proporcionado na brinquedoteca da ONG. Constatou-se que a brincadeira por si só traz muitas possibilidades para as crianças, no entanto, o espaço da brinquedoteca conta com um diferencial na potencialização dos efeitos positivos de qualquer brincar. Esse diferencial diz respeito à presença e à mediação do educador brinquedista.

Segundo Cadore (2006), o educador brinquedista é mediador do brincar na medida em que une dois polos: educar e brincar. Essa união se torna importante para nortear a ação deste educador, que deve criar um clima de encantamento, liberdade e sonho. A ação deste profissional está voltada para a criança e o adolescente, no sentido de compreender a importância do ato de brincar para cada sujeito, indo além do que se enxerga, para pressentir a seriedade daquele evento.

Observando as brincadeiras de Cláudio, Diego e André, e, consequentemente, o cotidiano na brinquedoteca, pode-se perceber a importância da mediação desses profissionais. Tentando me colocar como pesquisadora e não apenas como educadora brinquedista, notei, por exemplo, a mediação no sentido de integrar as crianças nas brincadeiras mais "exigentes", favorecendo a superação de dificuldades cognitivas. Um exemplo desse tipo de mediação ocorreu em uma das observações feitas com Cláudio: 
[...] chegamos à brinquedoteca [eu havia começado a jogar um jogo com outra menina e a brinquedista], $e$ perguntei a Cláudio se não gostaria de entrar no meu lugar no jogo. Ele observou um pouco o tabuleiro e respondeu que não. A brinquedista pediu [enquanto eu posicionava a câmera] que ele mostrasse a ela uma carta do jogo Detetive, e ele mostrou. Depois de posicionar a câmera sugeri então que jogássemos juntos. Cláudio a princípio recusou, mas acabou se sentando ao meu lado com minhas cartas na mão e encontrou uma função para si no jogo, mostrava minhas cartas aos outros jogadores.

Esse exemplo demonstra a forma como Cláudio pôde ser incluído no jogo sem ter que expor suas dificuldades. Ao mesmo tempo em que ajudava, sentindo-se importante com seu papel, se divertiu e treinou algumas habilidades que o jogo exigia.

A pesquisa tornou possível entender que o papel do educador brinquedista na mediação do livre-brincar pode potencializar os efeitos de resiliência que a própria atividade já oferece. Seja pelo vínculo afetivo, pelo incentivo à atividade lúdica sem restrições importantes, ou pela criação de um clima de encantamento, o educador brinquedista faz a diferença no ambiente da brinquedoteca, principalmente no que diz respeito ao potencial de resiliência alcançado pelas crianças.

\section{Conclusão}

Este estudo foi conduzido no sentido de entender se o livre-brincar realizado por três crianças institucionalizadas pode ter contribuído para que elas se tornassem indivíduos resilientes. Na literatura, encontrou-se que alguns fatores são importantes no desenvolvimento de indivíduos mais resilientes, como, por exemplo, a manutenção de vínculos fortes e duráveis; a confiança em pessoas e em si mesmo (autoestima) e o encantamento, que mantém a esperança em dias melhores.

Percebeu-se, ao longo da análise, que o brincar compõe uma parte muito importante na vida desses meninos, ajuda-os a expressar questões sobre as quais não conseguem ou não querem verbalizar, assim como permitindo que resgatem experiências positivas da infância, cujas histórias de vida difíceis impediram de acessar no momento devido. Cada um dos meninos, com suas particularidades e diversidade de brincadeiras, se aproximaram de diferentes possibilidades que o brincar proporciona.

André parece ter utilizado a brincadeira principalmente para dizer de si, do sofrimento que a doença lhe causa, e para superar a debilidade decorrente dessa doença. Por meio da música falou a respeito da doença; na fantasia pôde experimentar sensações de força e poder, e nas brincadeiras de pátio experimentou liberdade, porém com segurança. Acompanhar tal criança permitiu compreender que brincadeira se constitui como refúgio, e pôde ajudar o menino a superar condição de saúde frágil.

Cláudio apresentou brincadeiras quase sempre girando em torno de uma mesma temática: o futebol. A grande conclusão a respeito do brincar desse menino é que o esporte - transportado para o mundo da brincadeira - mantém a esperança dele em dias melhores. 0 sonho do futuro está ligado a essa atividade, e pôde ser experimentado no pátio da brinquedoteca. Em torno desse, e de outros brincares de Cláudio, alguns vínculos, a autoconfiança e a esperança puderam ser firmados.

Diego expressou muito de si em suas brincadeiras e experimentou possibilidades as quais não tem acesso atualmente. $\mathrm{O}$ faz-de-conta apareceu com personagens que diziam coisas importantes sobre si e que lhe permitiam se refugiar no mundo da fantasia. A brincadeira mais infantil permitiu um resgate da tenra infância, e talvez elaborações acerca desse momento passado. A convivência proporcionada pela brincadeira com outras crianças e adolescentes ampliou a rede de contatos de Diego e lhe forneceu artifícios para a vida fora do ambiente protegido do abrigo.

Este estudo se encerra, abrindo caminhos para outras pesquisas no tema da resiliência, com perguntas que surgiram e que permanecem sem resposta: "É possível uma forma de mensurar precisamente se uma pessoa é resiliente?"; "Os fatores que compõem um sujeito resiliente advêm apenas das experiências vividas e da forma como essas experiências são encaradas, ou existe um componente inato, a partir do qual alguns nascem mais predispostos a serem resilientes?".

Antes de encarar esses novos caminhos, esta pesquisa termina permitindo compreender que o livre-brincar e seus efeitos positivos podem, sim, contribuir para que crianças institucionalizadas se tornem resilientes. A partir dos diferentes tipos de brincar, a criança elabora conteúdos difíceis, fortalece vínculos afetivos e sua autoestima, resgata momentos da tenra 
infância, vislumbra seu futuro e mantém a esperança em dias melhores. É assim que acredito que o livre-brincar, especialmente o realizado na brinquedoteca e mediado pelos educadores brinquedistas, possibilita às crianças em situação de risco encontrar caminhos para superar as adversidades de suas vidas.

\section{Referências}

Assis, S. G., Pesce, R. P., \& Avanci, J. Q. (2006). Resiliência: Enfatizando a proteção dos adolescentes. Porto Alegre: Artmed.

Bettelheim, B. (1989). Compreendendo a importância da brincadeira. In B. Bettelheim. Uma vida para seu filho: Pais bons o bastante - ajude seu filho a ser a pessoa que ele deseja (pp. 156-166). Rio de Janeiro: Campus.

Bicudo, M. A. V., \& Martins, J. (1989). A pesquisa qualitativa em psicologia. In. M. A. V., Bicudo \& J. Martins. A pesquisa qualitativa em psicologia: Fundamentos e recursos básicos. São Paulo: Moraes.

Bomtempo, E. (1999). Brincar, fantasiar e aprender. Temas em Psicologia da SBP, 7(1), 51-56.

Cadore, I. F. (2006). Perfil do educador brinquedista. Palestra apresentada no III Curso de Formação de Educadores Brinquedistas e Organização de Brinquedotecas, Curitiba, Brasil.

Cunha, N. H. S. (2001). As diferentes formas de brincar. In N. H. S. Cunha. Brinquedoteca: Um mergulho no brincar (pp. 20-31). São Paulo: Vetor.

Grotberg, E. H. A. (1995). Guide to promoting resilience in children: Strengthening the human spirit. Civitan International Research Center. Birmingham: Alabama University. Recuperado em 20 abr. 2007, em http:// www.resilnet.uiuc.edu/library/grotb95b.html
Magalhães, C. M. C., \& Pontes, F. A. R. (2002). Criação e manutenção de brinquedotecas: Reflexões acerca do desenvolvimento de parcerias. Psicologia: Reflexão e Crítica, 15(1). Recuperado em 25 set. 2006, em http://www.scielo.br

Medrano, C. A. (2004). Do silêncio ao brincar: História do presente da saúde pública, da psicanálise e da infância. São Paulo: Vetor.

Paludo, S. S., \& Koller, S. H. (2005). Resiliência na rua: Um estudo de caso. Psicologia: Teoria e Pesquisa, 21(2). Recuperado em 12 set. 2006, em http://www. scielo.br

Santa Roza, E. (1999). Quando brincar é dizer. Rio de Janeiro: Contra Capa.

Verden-Zöller, G (2004). O Brincar na relação materno-infantil. In H. R Maturana \& G. Verden-Zöller (Org.). Amar e brincar: Fundamentos esquecidos do humano. (pp. 117-216). São Paulo: Pallas Athena.

Yunes, M. A. M. (2006). Psicologia positiva e resiliência: Foco no indivíduo e na família. In D. D Dell'aglio, S. H Koller \& M. A. M. Yunes. Resiliência e psicologia positiva: Interfaces do risco à proteção (pp. 45-68). São Paulo: Casa do Psicólogo.

Yunes, M. A. M., \& Szymanski, H. (2002). Resiliência: Noção, conceitos afins e considerações finais. In J. Tavares. Resiliência e educação (pp. 13-42). São Paulo: Cortez.

Zimmerman, M. A., \& Arunkumar, R. (1994). Resilience research: Implications for schools and policy. Social Policy Report, 8(1), 1-18. 